\title{
Explanations of variability in Middle Stone Age stone tool assemblage composition and raw material use in Eastern Africa
}

\author{
J. Blinkhorn ${ }^{1,2}$ (D) $\cdot$ M. Grove ${ }^{3}$ \\ Received: 26 February 2020 / Accepted: 1 December 2020 / Published online: 6 January 2021 \\ (C) The Author(s) 2020
}

\begin{abstract}
The Middle Stone Age (MSA) corresponds to a critical phase in human evolution, overlapping with the earliest emergence of Homo sapiens as well as the expansions of these populations across and beyond Africa. Within the context of growing recognition for a complex and structured population history across the continent, Eastern Africa remains a critical region to explore patterns of behavioural variability due to the large number of well-dated archaeological assemblages compared to other regions. Quantitative studies of the Eastern African MSA record have indicated patterns of behavioural variation across space, time and from different environmental contexts. Here, we examine the nature of these patterns through the use of matrix correlation statistics, exploring whether differences in assemblage composition and raw material use correlate to differences between one another, assemblage age, distance in space, and the geographic and environmental characteristics of the landscapes surrounding MSA sites. Assemblage composition and raw material use correlate most strongly with one another, with site type as well as geographic and environmental variables also identified as having significant correlations to the former, and distance in time and space correlating more strongly with the latter. By combining time and space into a single variable, we are able to show the strong relationship this has with differences in stone tool assemblage composition and raw material use, with significance for exploring the impacts of processes of cultural inheritance on variability in the MSA. A significant, independent role for terrain roughness for explaining variability in stone tool assemblages highlights the importance of considering the impacts of mobility on structuring the archaeological record of the MSA of Eastern Africa.
\end{abstract}

Keywords Eastern Africa $\cdot$ Middle Stone Age $\cdot$ Stone tools $\cdot$ Spatial analysis

\section{Introduction}

The archaeological record of the Middle Stone Age (MSA) in Eastern Africa has played a prominent role in debates surrounding the evolution of human behaviour. The Eastern African MSA record is particularly rich, revealed by an extensive research history (Basell 2008; Blinkhorn and Grove 2018; Clark 1988; Tryon and Faith 2013. Critically, recent research at Olorgesailie has identified the oldest MSA sites

J. Blinkhorn

blinkhorn@shh.mpg.de

1 Pan African Evolution Research Group, Max Planck Institute for the Science of Human History, Jena, Germany

2 Centre for Quaternary Research, Department of Geography, Royal Holloway, University of London, Egham, Surrey, UK

3 Department of Archaeology, Classics and Egyptology, University of Liverpool, Liverpool, UK across Africa, dating to 320-297 ka (Brooks et al. 2018; Deino et al. 2018; Potts et al. 2018). Notably, this overlaps with the earliest appearance of Homo sapiens fossils in the African record, dating to $300 \mathrm{ka}$ at Jebel Irhoud in Northern Africa (Hublin et al. 2017). This significantly precedes the Eastern African fossil record for Homo sapiens (McDougall et al. 2005), which formerly led to a strong focus on the region as the centre of endemism for modern humans. Such straightforward associations between any single African region and the appearance of Homo sapiens appear increasingly untenable, with the growing acknowledgement that complex population interactions across the continent are likely to have occurred (Scerri et al. 2018). Nevertheless, the Eastern African MSA record remains an important testing ground for hypotheses regarding behavioural change over a critical period in human evolution.

Characterising the MSA of Eastern Africa has proved complex as there are no behavioural features that are ubiquitous within the archaeological record that span the early emergence 
of MSA assemblages in Marine Isotope Stage (MIS) 9 until its final appearance in the region during MIS 3 (Blinkhorn and Grove 2018). Nevertheless, common typological features of stone tool assemblages attributed to the MSA include the use of varied Levallois methods, the focus on a diverse retouched tool kit focusing upon medium-sized flakes, and the proliferation of point technologies. Late Acheulean technologies persist in the region until $212 \mathrm{ka}$ at Mieso (De la Torre et al. 2014), with MSA industries typically focusing on more finegrained raw materials with a decreased use and diversity of heavy tools employed. Later Stone Age industries first appear in the region from $64 \mathrm{ka}$ at Panga ya Saidi (Shipton et al. 2018), marked by a significant shift in artefact size associated with the increased prominence of microlithic tools and bipolar technology, along with a further change in raw material preference, including more widespread exploitation of quartz.

Identifying clear patterns of behaviour across the MSA record of Eastern Africa has proved complex. The recent application of quantitative methods to examine the diversity of archaeological assemblages has begun to illuminate some trends. Tryon and Faith (2013) applied correspondence analyses to a presence/absence dataset of key artefact types including lithic artefacts, beads and ochre, identifying a chronological distinction between earlier (before MIS 5) and later (MIS 5-3) assemblages. Further to this, a regression analysis was conducted on the distance between sites and a Dice-Sorensen index calculated from the same dataset, indicating a weak but significant trend of increasing difference in behaviour with distance (Tryon and Faith 2013). Recently, we examined an expanded dataset of lithic artefact typology alongside geographic and environmental parameters using a combination of dissimilarity matrices and hierarchical clustering (Blinkhorn and Grove 2018). This highlighted a tripartite split of the MSA record, between assemblages dating to MIS 5 and those that precede and succeed them, defined two common core clusters of stone tool types, illuminated the diversity and structure of geographic and environmental settings of MSA sites and identified pulsed patterns of occupation intensity and shifting patterns of landscape colonisation through time (Blinkhorn and Grove 2018). Here, we expand upon the use of dissimilarity matrices to examine a presence/absence dataset of lithic artefact types using matrix correlations.

Mantel tests examine correlations between dissimilarity matrices (Mantel 1967). As dissimilarity matrices do not present independent data points, significance testing is achieved through a process of multiple random permutations of one of the matrices to evaluate the proportion of correlation coefficients that are greater than that with the original matrix. Partial Mantel tests and multiple matrix (or multiple Mantel) regression follow similar procedure whilst controlling for the impact of a third or multiple additional matrices respectively (Legendre et al. 2015; Smouse et al. 1986). These tests present the means to investigate causal relationships between distance matrices rather than between the paired vectors themselves. Such methods have been routinely employed in population studies and ecology (Legendre 2000; Legendre et al. 2015), and lately, both simple and partial Mantel tests have begun to be used more frequently amongst archaeologists and anthropologists. Buchanan and Hamilton (2009) used simple and partial Mantel tests to examine variability in early Paleoindian projectile points, suggesting functional modifications as adaptations to different biomes were minimal and emphasising the impact of spatial autocorrelation. Ross et al. (2013) used these methods to identify independent effects of geographical distance and ethnolinguistic affiliation upon folktale diversity. Brown et al. (2013) employ Mantel tests to demonstrate significant and discrete correlations between genetic diversity and both musical and linguistic traditions. Shennan et al. (2015) employ matrix correlations to examine the impact of isolation by distance on stylistic features of pottery and jewellery assemblages from Neolithic Europe compared to cultural affiliation. Lycett (2018) employs these methods to determine the impact of isolation by distance in beadwork designs and manufacture amongst historic-era Great Plains populations. Alongside their use in other disciplines, these studies illustrate the potential of these methods to explore archaeological and anthropological questions. Isolation by distance (Wright 1943) plays a prominent role in studies that employ matrix correlations, drawing upon their significance in population biology and ecology, although the examples noted above clearly demonstrate the potential to examine other forms of dissimilarity, including distances in behaviour, time, geography and ecology.

\section{What explains difference in stone tool composition}

A range of factors may influence the composition of stone tool assemblages (Andrefsky 2008). Firstly, different approaches to the practice of archaeology can affect the composition of stone tool assemblages. The method of reporting stone tools can impact the evaluation of lithic assemblage diversity, as researchers employ different typological schemes that may split or lump the reporting of certain artefact forms (Whittaker et al. 1998). Artefact assemblages from surface surveys may differ in composition for those recovered by systematic excavations, whilst larger excavations or more systematic survey protocols may recover larger stone tool assemblages with a chance of sampling greater behavioural diversity. Whilst partly governed by depositional processes and factors of preservation, as well as past behaviour, the examination of caves and rock shelters in contrast to open-air sites is also a choice that features in archaeological fieldwork design. It is also critical to be aware that examination of Stone Age 
archaeological sites involves studies of palimpsests of behaviour that can range between a small number of knapping episodes to those that spanned many generations (Bailey 2007).

Secondly, stone tools have played a significant functional role in the lives of past populations, and as such, assemblage composition may reflect the impact of varied practical concerns. Functional impacts on assemblage composition may be manifest in multiple, overlapping ways. The dichotomy of residential and logistic hunter-gatherer sites (Binford 1980) likely compresses much variability as to how sites identified by archaeologists were occupied and used by past populations but does characterise differences between generalised, larger and longer-term occupations likely to record a broader range of reduction activities and smaller, specialised occupations that may record only a subset of a wider technological repertoire. Geographic factors, such as altitude and roughness of terrain, can significantly impact patterns of mobility amongst human populations as well as faunal and floral communities that present the subsistence base (Binford 2019), such that alternate stone tools or combinations of them may yield functional advantages in different geographic contexts. Similarly, environmental factors, including patterns of temperature and precipitation, can drive substantive differences in ecology and patterns of engagement by hunter-gatherer populations (Binford 2019) for which alternate combinations of stone tools may offer differing functional advantages. Critically, the individual tools may not represent finalised forms but rather occur as part of a reduction continuum (Rolland and Dibble 1990), and the intensity of artefact reduction prior to entering the archaeological record may reflect the variety of factors discussed above. A significant body of research has documented the impact of using differing raw materials upon lithic reduction practices yet beyond the functional constraints of differing fracture mechanics between alternate materials for controlling the reduction process, access to alternate raw materials, the clast size available, distribution in the landscape and proximity to an occupation site and the impact of material crystal structure on tool use may all impact raw material choices (Andrefsky 1994; Eren et al. 2014b). Such functional constraints are likely to have been engaged with through a social lens, with multiple alternative behavioural strategies possible, though strategies in which basic subsistence needs cannot be met are unlikely to have been long lasting (see Tostevin 2013).

Stone tool reduction practices that create archaeological assemblages are transmitted between individuals and groups through cultural transmission and may be subject to both neutral and directional selections (Creanza et al. 2017). The examination of behavioural variability through time and space plays a foundation role in archaeological research. Within biological studies, isolation by distance (Wright 1943) is a key concept suggesting increasing genetic differences are likely to occur between populations that are separated by larger geographic distances as a result of reproductive isolation. This presents an analogy for cultural variability, in which greater cultural differences may be anticipated between populations that are separated by larger distances in space and time, as a result of decreased opportunity for high fidelity transmission of cultural transmission and increased opportunity for either random or adaptive variations to cultural practice. It is important to note that the factors noted above may impact the influence of distance through time and space. For example, greater cultural differences could occur between stone tool assemblages located within closer geographic proximity to one another but in starkly different ecological contexts compared to those at greater geographic distances within similar habitats. Finally, population size, population structure and the scale of population mobility are all recognised as features that influence both the rate of behavioural innovation and potential patterns of cultural transmission (Powell et al., 2009; Shennan et al. 2015; Loog et al. 2017).

The aim of this paper is to examine the extent to which a range of these factors can explain the variability between stone tool assemblages spanning the Eastern African MSA record. We employ simple and partial Mantel tests to examine correlations between dissimilarity matrices for stone tool assemblage composition and a range of factors described above. We examine whether distance in behaviour is correlated to distance in raw material use, site type, investigative strategy, age, location, the combination of time and space, and a range of characteristics of site environments at $5-\mathrm{km}$ and $50-\mathrm{km}$ radii, including Altitude, roughness of terrain and mean annual temperature and precipitation for modern conditions and modelled arid and humid conditions. We then explore the extent to which such correlations are independent of one another. By demonstrating the impact of archaeological and functional constraints on our understanding of past behavioural variability, we hope to identify avenues to pursue the role of cultural forces on behavioural evolution in Stone Age Eastern Africa.

\section{Datasets and methods}

The dataset is derived from the Eastern African literature, including typology, chronometric ages, raw material use and location, building on the dataset from Blinkhorn and Grove (2018). Stone tool assemblages were included in the dataset for analysis where details of raw material use, the method of investigation (survey or excavation) and site type (open-air or cave/rock shelter) are reported and a minimum and maximum age estimate is available. The sites, assemblages, locations, method of investigation and site type along with the minimum and maximum age and key references are listed in Table 1, and their locations are illustrated in Fig. 1. 
Table 1 List of sites and assemblages used in the analysis, including details of location (latitude and longitude), whether the assemblage was recovered from surface or by excavation, whether from an open-air site
(OpenAir) or from a cave or rock shelter (Cave/RS), and the minimum and maximum age estimates reported, along with key references

\begin{tabular}{|c|c|c|c|c|c|c|c|}
\hline Assemblage & Method & Site & Latitude & Longitude & Min Age & Max Age & Reference \\
\hline Abdur_N_C_S & Excavation & OpenAir & 15.13 & 39.68 & 118 & 132 & $\begin{array}{l}\text { Bruggemann 2004; } \\
\quad \text { Walter et al. } 2000\end{array}$ \\
\hline AdumaA1 & Excavation & OpenAir & 10.39 & 40.54 & 80 & 100 & Yellen et al. 2005 \\
\hline AdumaA4C & Excavation & OpenAir & 10.39 & 40.54 & 80 & 100 & Yellen et al. 2005 \\
\hline AdumaA5Ex & Excavation & OpenAir & 10.39 & 40.54 & 80 & 100 & Yellen et al. 2005 \\
\hline AdumaA5ExSurf & Excavation & OpenAir & 10.39 & 40.54 & 80 & 100 & Yellen et al. 2005 \\
\hline AdumaA8 & Excavation & OpenAir & 10.39 & 40.54 & 80 & 100 & Yellen et al. 2005 \\
\hline AdumaA8AC & Excavation & OpenAir & 10.39 & 40.54 & 80 & 100 & Yellen et al. 2005 \\
\hline AdumaA8AG & Excavation & OpenAir & 10.39 & 40.54 & 80 & 100 & Yellen et al. 2005 \\
\hline AdumaA8ASurf & Excavation & OpenAir & 10.39 & 40.54 & 80 & 100 & Yellen et al. 2005 \\
\hline AdumaA8B & Excavation & OpenAir & 10.39 & 40.54 & 80 & 100 & Yellen et al. 2005 \\
\hline AdumaVP1/1 & Surface & OpenAir & 10.39 & 40.54 & 80 & 100 & Yellen et al. 2005 \\
\hline AdumaVP1/3 & Surface & OpenAir & 10.39 & 40.54 & 80 & 100 & Yellen et al. 2005 \\
\hline Enkapune_ya_Muto_RBL4 & Excavation & Cave/RS & 0.00 & 36.15 & 43 & 45 & Basell 2008 \\
\hline EyasiShore_77_81 & Excavation & OpenAir & -3.54 & 35.28 & 91 & 132 & Mehlman 1989 \\
\hline EyasiShore_N_surface & Surface & OpenAir & -3.54 & 35.28 & 91 & 132 & Mehlman 1989 \\
\hline EyasiShore_W_insitu & Excavation & OpenAir & -3.54 & 35.28 & 91 & 132 & Mehlman 1989 \\
\hline EyasiShore_W_surf & Surface & OpenAir & -3.54 & 35.28 & 91 & 132 & Mehlman 1989 \\
\hline Fincha Habera 8_10 & Excavation & Cave/RS & 7.01 & 39.72 & 27 & 34 & Ossendorf et al. 2019 \\
\hline Fincha Habera 8_11 & Excavation & Cave/RS & 7.01 & 39.72 & 27 & 34 & Ossendorf et al. 2019 \\
\hline Fincha Habera 8_8 & Excavation & Cave/RS & 7.01 & 39.72 & 27 & 34 & Ossendorf et al. 2019 \\
\hline Fincha Habera $8 \_9$ & Excavation & Cave/RS & 7.01 & 39.72 & 27 & 34 & Ossendorf et al. 2019 \\
\hline Fincha Habera 9 & Excavation & Cave/RS & 7.01 & 39.72 & 33 & 42 & Ossendorf et al. 2019 \\
\hline Gademotta_ETH72_1 & Excavation & OpenAir & 7.55 & 38.57 & 172 & 274 & Douze 2012 \\
\hline Gademotta_ETH72_6 & Excavation & OpenAir & 7.55 & 38.57 & 172 & 274 & Douze 2012 \\
\hline Goda Butchia_Complex2_DEF & Excavation & Cave/RS & 9.54 & 41.63 & 22 & 70 & Leplongeon et al. 2017 \\
\hline KapedoTuffs & Surface & OpenAir & 1.07 & 36.08 & 120 & 135 & Tryon et al. 2008 \\
\hline KapForm_KoimilotGnJh74_1 & Excavation & OpenAir & 0.52 & 35.98 & 198 & 237 & Tryon 2003 \\
\hline KapForm_KoimilotGnJh74_2 & Excavation & OpenAir & 0.52 & 35.98 & 198 & 237 & Tryon 2003 \\
\hline KapForm_SSRS & Excavation & OpenAir & 0.66 & 35.99 & 198 & 237 & Blegen 2017 \\
\hline Karungu_A3Ex & Excavation & OpenAir & -0.84 & 34.18 & 42 & 115 & Faith et al. 2015 \\
\hline Karungu_Kisaaka_Main & Surface & OpenAir & -0.81 & 34.13 & 42 & 56 & Faith et al. 2015 \\
\hline Karungu_Kisaaka_ZTG & Surface & OpenAir & -0.81 & 34.13 & 42 & 115 & Faith et al. 2015 \\
\hline Kiese II_18 & Excavation & Cave/RS & -4.49 & 35.81 & 38 & 39 & Tryon et al. 2018 \\
\hline Kiese II_19 & Excavation & Cave/RS & -4.49 & 35.81 & 31 & 46 & Tryon et al. 2018 \\
\hline Kiese II_20 & Excavation & Cave/RS & -4.49 & 35.81 & 42 & 45 & Tryon et al. 2018 \\
\hline Kiese II_21 & Excavation & Cave/RS & -4.49 & 35.81 & 43 & 46 & Tryon et al. 2018 \\
\hline LaasGeel_SU_711 & Excavation & Cave/RS & 9.69 & 44.27 & 40 & 42 & Gutherz et al. 2014 \\
\hline LukenyaHill_GvJm46 & Excavation & OpenAir & -1.66 & 37.14 & 21 & 27 & Kelly 1996; Basell 2008 \\
\hline $\begin{array}{l}\text { LukenyaHillGvJm22_F170_ } \\
\quad 205\end{array}$ & Excavation & Cave/RS & -1.66 & 37.14 & 25 & 32 & Tryon et al. 2015 \\
\hline Magubike_MSA & Excavation & Cave/RS & -7.76 & 35.47 & 35 & 48 & Bushozi 2011 \\
\hline MalewaGorge & Surface & OpenAir & -0.77 & 36.39 & 240 & 240 & Basell 2008 \\
\hline Marmonet Drift_H2 & Excavation & OpenAir & -0.76 & 36.18 & 89 & 205 & Slater 2016 \\
\hline Marmonet Drift_H4 & Excavation & OpenAir & -0.76 & 36.18 & 90 & 130 & Slater 2016 \\
\hline
\end{tabular}


Table 1 (continued)

\begin{tabular}{|c|c|c|c|c|c|c|c|}
\hline Assemblage & Method & Site & Latitude & Longitude & Min Age & Max Age & Reference \\
\hline Marmonet Drift_H5 & Excavation & OpenAir & -0.76 & 36.18 & 90 & 98 & Slater 2016 \\
\hline Marmonet Drift_I_bottom & Excavation & OpenAir & -0.76 & 36.18 & 205 & 257 & Ambrose \& Deino 2010 \\
\hline MochenaBorago_LowerT & Excavation & Cave/RS & 6.90 & 37.75 & 49 & 50 & Brandt et al. 2017 \\
\hline MochenaBorago_RGroup & Excavation & Cave/RS & 6.90 & 37.75 & 36 & 43 & Brandt et al. 2017 \\
\hline MochenaBorago_SGroup & Excavation & Cave/RS & 6.90 & 37.75 & 43 & 46 & Brandt et al. 2017 \\
\hline MochenaBorago_UpperT & Excavation & Cave/RS & 6.90 & 37.75 & 45 & 49 & Brandt et al. 2017 \\
\hline Mumba_L_III_38 & Excavation & Cave/RS & -3.54 & 35.30 & 33 & 40 & Mehlman 1989 \\
\hline Mumba_L_V_81 & Excavation & Cave/RS & -3.54 & 35.30 & 52 & 61 & Mehlman 1989 \\
\hline Mumba_L_VI_38 & Excavation & Cave/RS & -3.54 & 35.30 & 52 & 61 & Mehlman 1989 \\
\hline Mumba_L_VI_A & Excavation & Cave/RS & -3.54 & 35.30 & 86 & 115 & Mehlman 1989 \\
\hline Mumba_MU_V_81 & Excavation & Cave/RS & -3.54 & 35.30 & 47 & 55 & Mehlman 1989 \\
\hline Mumba_U_V_38 & Excavation & Cave/RS & -3.54 & 35.30 & 44 & 53 & Mehlman 1989 \\
\hline Mumba_U_VI_A & Excavation & Cave/RS & -3.54 & 35.30 & 57 & 69 & Mehlman 1989 \\
\hline Mumba_VI_B & Excavation & Cave/RS & -3.54 & 35.30 & 86 & 153 & Mehlman 1989 \\
\hline Nasera_12_17 & Excavation & Cave/RS & -2.74 & 35.36 & 53 & 58 & Mehlman 1989 \\
\hline Nasera_6_7 & Excavation & Cave/RS & -2.74 & 35.36 & 50 & 58 & Mehlman 1989 \\
\hline Nasera_8/9_11 & Excavation & Cave/RS & -2.74 & 35.36 & 50 & 58 & Mehlman 1989 \\
\hline Ndutu_14 & Surface & OpenAir & -3.25 & 34.87 & 220 & 240 & Eren et al. 2014a, b \\
\hline Ndutu_72 & Surface & OpenAir & -3.25 & 34.87 & 220 & 240 & Leakey et al. 1972 \\
\hline Olorgesailie_BOK1E & Excavation & OpenAir & -1.57 & 36.43 & 295 & 320 & Brooks et al. 2018 \\
\hline Olorgesailie_BOK2 & Excavation & OpenAir & -1.57 & 36.43 & 295 & 320 & Brooks et al. 2018 \\
\hline Olorgesailie_BOK3 & Excavation & OpenAir & -1.57 & 36.43 & 295 & 320 & Brooks et al. 2018 \\
\hline Olorgesailie_BOK4 & Excavation & OpenAir & -1.57 & 36.43 & 288 & 301 & Brooks et al. 2018 \\
\hline Omo_AHS1-5 & Excavation & OpenAir & 4.47 & 35.98 & 193 & 201 & Shea 2008 \\
\hline Omo_AHS6_8 & Excavation & OpenAir & 4.47 & 35.98 & 193 & 201 & Shea 2008 \\
\hline Omo_AHSsurface & Surface & OpenAir & 4.47 & 35.98 & 193 & 201 & Shea 2008 \\
\hline Omo_BNS_L3 & Excavation & OpenAir & 4.47 & 35.98 & 96 & 111 & Shea 2008 \\
\hline Omo_BNS $<50 \mathrm{~m}$ & Surface & OpenAir & 4.47 & 35.98 & 96 & 111 & Shea 2008 \\
\hline Omo_KHS2/3 & Excavation & OpenAir & 4.47 & 35.98 & 193 & 201 & Shea 2008 \\
\hline Omo_KHSNgully & Surface & OpenAir & 4.47 & 35.98 & 193 & 201 & Shea 2008 \\
\hline Omo_KHSNMKenya & Surface & OpenAir & 4.47 & 35.98 & 193 & 201 & Shea 2008 \\
\hline Omo_KHSSgully & Surface & OpenAir & 4.47 & 35.98 & 193 & 201 & Shea 2008 \\
\hline Pange_ya_Saidi_17 & Excavation & Cave/RS & -3.72 & 39.72 & 65 & 80 & Shipton et al. 2018 \\
\hline Pange_ya_Saidi_18 & Excavation & Cave/RS & -3.72 & 39.72 & 67 & 86 & Shipton et al. 2018 \\
\hline Pange_ya_Saidi_19 & Excavation & Cave/RS & -3.72 & 39.72 & 67 & 86 & Shipton et al. 2018 \\
\hline Rusinga_Nyamita & Surface & OpenAir & -0.43 & 34.16 & 42 & 56 & Tryon et al. 2012 \\
\hline Shurmai_MSA & Excavation & Cave/RS & 0.51 & 37.22 & 39 & 50 & Dickson and Gang 2002 \\
\hline VictoriaCabera_2 & Excavation & OpenAir & -2.99 & 35.35 & 70 & 91 & Maíllo-Fernández et al. 2019 \\
\hline VictoriaCabera_2a & Excavation & OpenAir & -2.99 & 35.35 & 70 & 91 & Maíllo-Fernández et al. 2019 \\
\hline VictoriaCabera_3 & Excavation & OpenAir & -2.99 & 35.35 & 70 & 91 & Maíllo-Fernández et al. 2019 \\
\hline VictoriaCabera_4 & Excavation & OpenAir & -2.99 & 35.35 & 79 & 91 & Maíllo-Fernández et al. 2019 \\
\hline
\end{tabular}

The stone artefact typology used here follows Grove and Blinkhorn (2020). Terms used include the following: Backed/ Microliths, BipolarTech, BladeTech, Borer, Burin, CentripetalTech, CoreTool, Denticulate, LevalloisBladeTech, LevalloisFlakeTech, LevalloisPointTech, Notch,
PlatformCore, PointTech, RTBifacial and Scraper. These terms are described in SI and the relationship between these terms are original terminology reported in the literature are set out in Table S1. The presence of at least two of the artefact types was required for inclusion of an assemblage in the dataset. 
This typology is derived from patterns of terminological use in the literature to enable a wide as possible synthesis of data, with potential drawbacks of this approach discussed in Blinkhorn and Grove (2018). All reports of raw material use were recorded grouped into one of eight categories, based upon their frequency, all of which occur in a minimum of 8 different assemblages: cherts, quartzs, obsidians, basalts, metamorphics, cryptocrystalline silica (CCS), other igneous and sedimentary. These data are illustrated in Fig. 2.

Site types were recorded as either open-air sites or rock shelters and caves. The method of archaeological investigation was recorded as either excavation or survey. Artefact assemblages are only included in the dataset for analyses when they can be ascribed a minimum and maximum age, based upon reports from the literature. Raw data for radiocarbon dates were recorded and calibrated using the IntCal13 curve using the bchron v4.3 package (Parnell 2018) in R. A simple age estimate for each assemblage is provided by the mid-point between the minimum and maximum age. Additional data employed in the study include the SRTM 1-km DEM (Jarvis et al. 2008), and annual precipitation and temperature datasets for modern (MOD), last glacial maximum (LGM) and last interglacial (LIG) timeframes from www.worldclim.org, scaled between 0 and 1. We employ modern, LGM and LIG temperature and precipitation datasets as a means to bracket the scale of likely Late Pleistocene environmental variability in the absence of comparable proxy records from all sites included in the analysis.

Within the methods presented below and the results section, the differences between sites in each variable, which comprise the dissimilarity matrices, are referred to by the name of the variable highlighted in italics (e.g. Behaviour). The presence of stone tool types and raw material types were coded as present (1) or absent (0) and dissimilarity matrices (Behaviour; RawMat) calculated using Jaccard's coefficient,
Fig. 1 Location map of Eastern African MSA sites included in the analysis, illustrating their location on an SRTM-DEM (Jarvis et al. 2008)

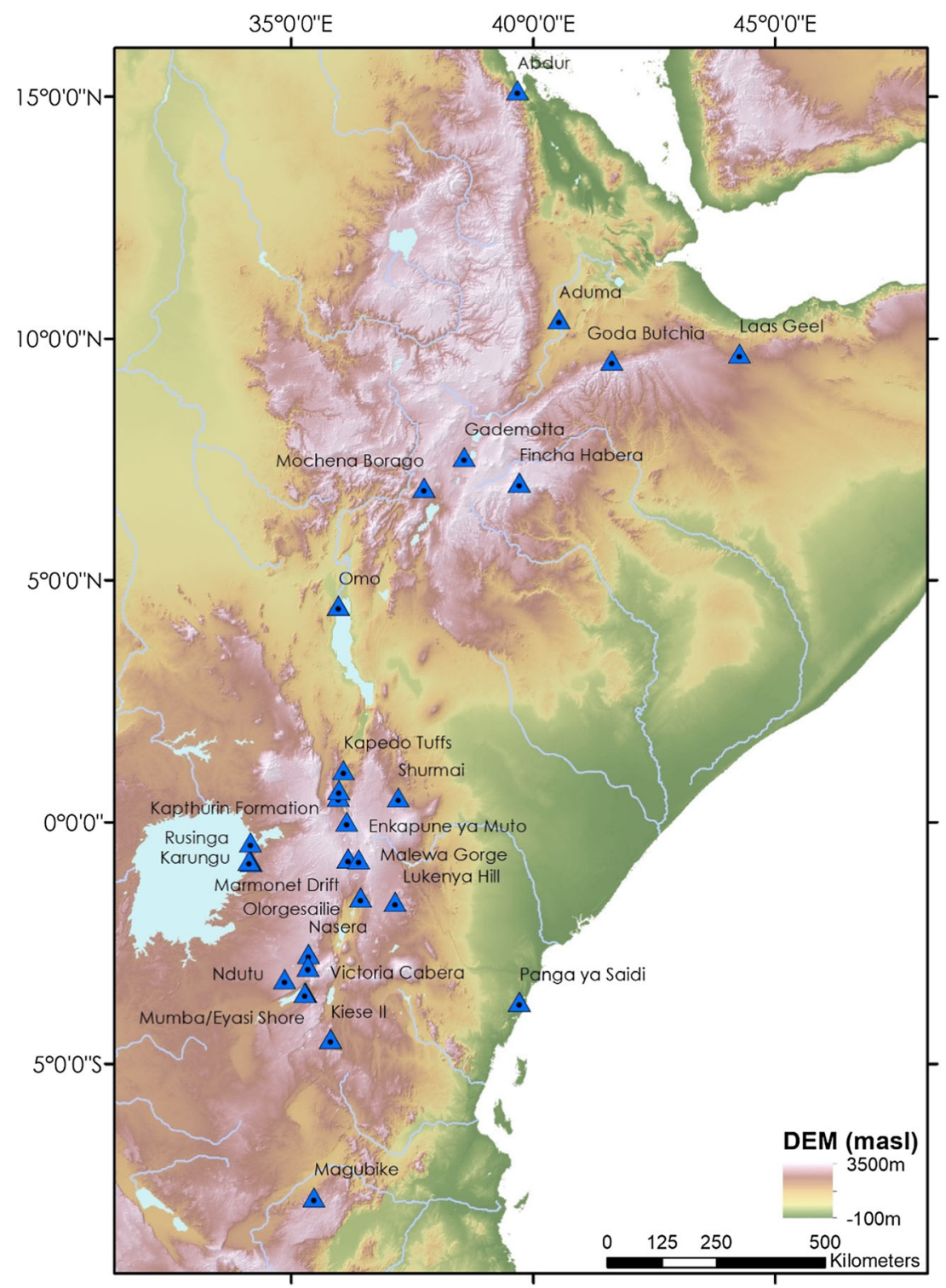



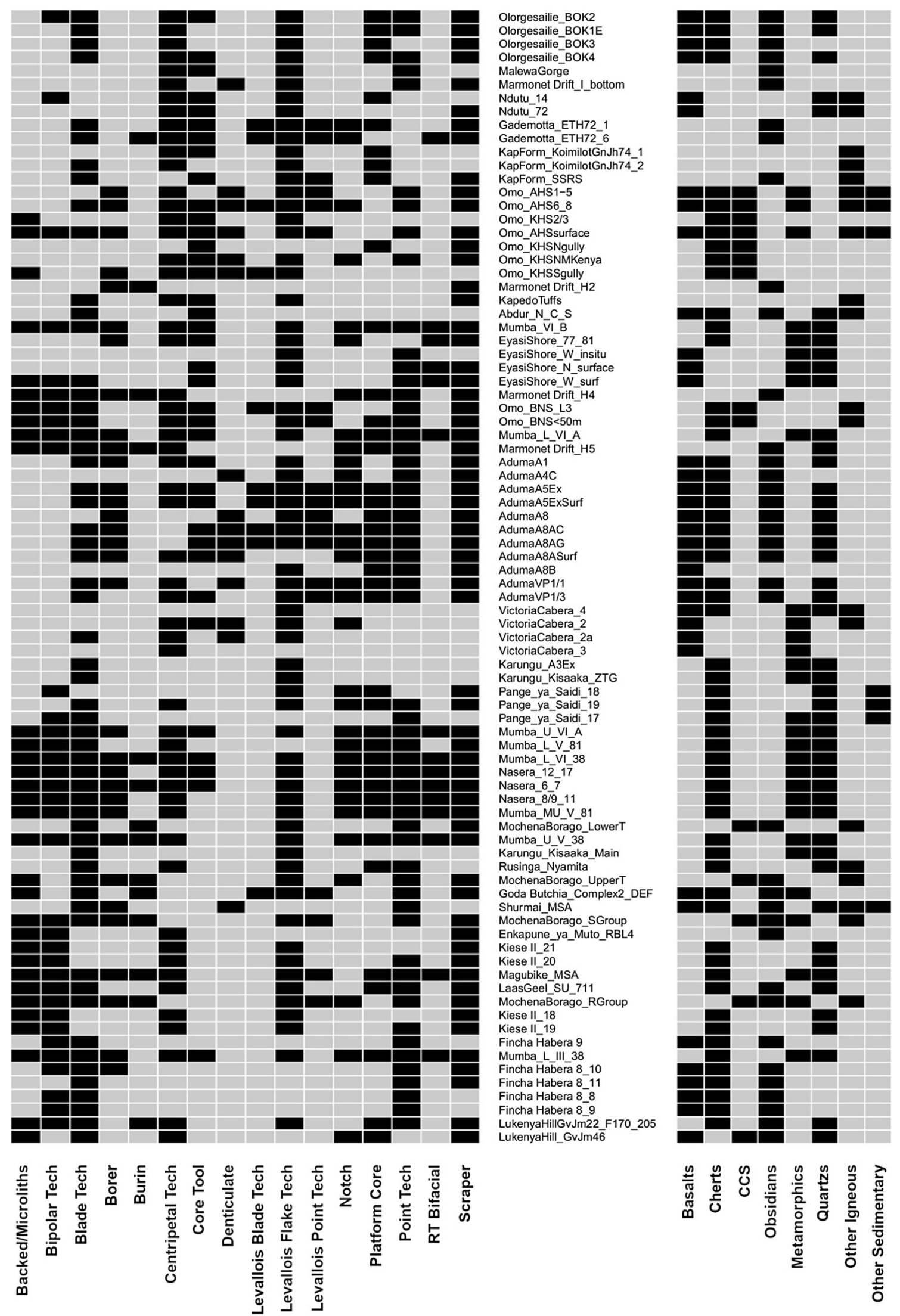

Fig. 2 Binary matrix of presence and absence of artefact types (left) and raw material types (right) for Middle Stone Age sites in Eastern Africa, ordered from oldest (top) to youngest (bottom) 
which excludes the impact of shared absences from calculations. Site type and investigation method were coded as discrete binary variables (e.g. open air $=0$; rock shelter $/$ cave $=1$ ) for calculation of dissimilarity matrices (Site; Method [see Table 1]), also using Jaccard's coefficient. A simple estimate of distance in time between sites was achieved by subtracting the younger age from the older age to produce a dissimilarity matrix based on mid-point between the maximum and minimum assemblage ages (Age). For example, the mid-point between minimum $(80 \mathrm{ka})$ and maximum $(100 \mathrm{ka})$ ages at Aduma is $90 \mathrm{ka}$.

Distances between sites (Costpath) were calculated as cost paths using Tobler's function for speed of movement across terrain as a factor of changing slope derived from the SRTM 1km DEM, using the gdistance package (van Etten 2017), with major water bodies (e.g. Lake Turkana) masked from the analysis. Following Blinkhorn and Grove (2018) we derived a raster dataset from the SRTM DEM (Jarvis et al. 2008) relating to slope of the terrain, which were transformed to values of energy expenditure (Joules per metre per second) following Minetti et al. (2015) (Roughness). This accounts for the fact that differences in cost of moving on flat ground vs $10^{\circ}$ slopes compared to $10^{\circ}$ and $20^{\circ}$ slopes are not equal, although the differences in slope are the same. For this raster dataset (Roughness), as well as altitude and both modern and modelled past climatic conditions, buffers were created around site locations with a radius of $5 \mathrm{~km}$ and $50 \mathrm{~km}$ to examine the immediate residential landscape of the site $(5 \mathrm{~km})$ and the broader logistical terrain in which it is situated $(50 \mathrm{~km})$, creating histogram datasets. The distance matrices for these histogram-based datasets (Roughness, Altitude, MOD/LGM/ LIG temp and precip at both $5-\mathrm{km}$ and $50-\mathrm{km}$ scales [e.g. MODprecip50km]) were calculated using the L2 Wasserstien metric (Irpino 2017).

Loog et al. (2017) highlight the impact of changing mobility of past populations on patterns of isolation by distance and time, and present a method to combine these two factors into a single extra-correlated variable that recognised impacts of both dimensions on cultural inheritance. Whilst both increased spatial separation of contemporaneous populations or chronological separation within occupation of single site could impact patterns of cultural inheritance, the combination of distance in space and time is likely to compound this effect. We generated 9999 incremental combinations of the distance matrices for Age and Costpath distance, from 1/9999 contribution to 9998/9999 contribution of Costpath distance. Mantel tests were conducted for each of these 9999 composite timespace matrices with behavioural distance to identify which combination of Age and Costpath distance produced the strongest relationship with behavioural distance. This resulted in the identification of an extra-correlated relationship to behavioural distance with a ratio of contribution from Costpath and Age distance of 1.603 to produce the dissimilarity matrix (Timespace).
The null hypothesis of simple Mantel tests, partial Mantel tests and multiple matrix regression is that there is no correlation between two dissimilarity matrices, factoring in the impact of additional variables for partial Mantel tests and multiple matrix regressions. For example, the null hypothesis for simple Mantel test between Behaviour and Costpath is that no relationship exists in how dissimilar archaeological assemblages are with regards to the difference in cost in moving between the sites where assemblages are found. The alternative hypothesis, therefore, is that there is a relationship between the dissimilarity in these variables, in the form of either a positive or negative correlation. For example, a positive correlation in dissimilarity may exist, such that sites that are close together (i.e. low dissimilarity in Costpath) may share more similar constellations of stone tool types (i.e. low dissimilarity in Behaviour), with high dissimilarity in Costpath distance correlating to high dissimilarity in distance for behaviour. A negative correlation suggests that as dissimilarity increases in one variable, it decreases in another.

Simple Mantel tests were then conducted between behaviour and all other matrices in $\mathrm{R}$ using the vegan package (Oksanen et al. 2019) and employing 9999 permutations to obtain $p$ values. In this process, the rows and columns of one matrix are randomly permuted and Pearson's correlation coefficients are calculated, ranging from 1 to -1 . The significance of correlation between the un-permuted matrices is derived from the proportion of permuted $r$ values that are higher than that of the un-permuted $r$ value. Partial Mantel tests (also conducted using vegan and 9999 permutations) were then calculated with controlling variables identified in light of simple Mantel tests: Method and Site, RawMat, Altitude and Roughness, MODPrecip $50 \mathrm{~km}$, MODTemp $50 \mathrm{~km}$ and LGMTemp50km, LGMPrecip50km, Age, Costpath and Timespace. Finally, multiple matrix regression examined significant correlations between Behaviour and RawMat, Method, Site, Age, Costpath, Altitude50km, Roughness50km, $M O D$ precip $50 \mathrm{~km}$ and MODtemp50km (as an enter, rather than stepwise, procedure) controlling for the impact of multiple response variables, with 9999 permutations using the phytools package in R (Revell 2012). In all cases, test statistics reported are produced via permutation. Further testing was undertaken employing the same methods described above to examine the relationships between raw material use and other variables. The Benjamini-Hochberg procedure is used to adjust $p$ values for simple and partial Mantel tests.

\section{Results}

\section{Simple Mantel tests}

A number of significant correlations are observed between distance in assemblage composition and other variables 
(Table 2). Behavioural distance (Behaviour) amongst MSA sites is most strongly (and significantly) correlated with RawMat. Roughness $50 \mathrm{~km}$ shows comparable strength of relationship to Behaviour as RawMat, but the weakest relationship across all variables at the $5-\mathrm{km}$ scale (Roughness $5 \mathrm{~km}$ ). Site altitude shows strong correlations to behavioural distance for both $50-\mathrm{km}$ and $5-\mathrm{km}$ scales, with temperature variables showing stronger correlations than precipitation variables, with stronger correlations typically observed across both groups at the $5-\mathrm{km}$ rather than $50-\mathrm{km}$ scale. Only LGmPrecip50km does not show a correlation to behavioural distance that is statistically significant with an alpha $=0.05$ threshold when adjusted. Differences in the extra-correlated Timespace variable are significantly correlated Behaviour, as is Costpath, but differences in Age alone are not. Site exhibits a significant correlation to behavioural distance, although Method does not.

Simple Mantel tests suggest both similarities and differences to the patterns described above when the correlations

Table 2 Results of simple Mantel tests between the presence and absence of either key MSA artefact types (behaviour) and raw material use (raw material), and other variables spanning time, space, geography and ecology. $p$ values from individual tests are reported, with statistically significant results after $p$-adjustment highlighted in bold

\begin{tabular}{|c|c|c|c|c|}
\hline & \multicolumn{2}{|c|}{ Behaviour } & \multicolumn{2}{|c|}{ Raw material } \\
\hline & Statistic & $p$ value & Statistic & $p$ value \\
\hline Behaviour & NA & NA & 0.2539 & 0.0001 \\
\hline RawMat & 0.2539 & 0.0001 & NA & NA \\
\hline Method & 0.0515 & 0.1876 & 0.0798 & 0.0562 \\
\hline Site & 0.1519 & 0.0002 & 0.0591 & 0.0209 \\
\hline Age & 0.0798 & 0.0773 & 0.1436 & 0.0025 \\
\hline Costpath & 0.1139 & 0.0053 & 0.1604 & 0.0002 \\
\hline Timespace & 0.1449 & 0.0007 & 0.2234 & 0.0001 \\
\hline Altitude $50 \mathrm{~km}$ & 0.1868 & 0.0007 & 0.1075 & 0.0092 \\
\hline Roughness $50 \mathrm{~km}$ & 0.2404 & 0.0002 & 0.0305 & 0.2429 \\
\hline LGMprecip50km & 0.1101 & 0.0432 & 0.1037 & 0.0235 \\
\hline LGMtemp $50 \mathrm{~km}$ & 0.1733 & 0.0015 & 0.1914 & 0.0001 \\
\hline LIGprecip50km & 0.1204 & 0.0097 & 0.1775 & 0.0001 \\
\hline LIGtemp $50 \mathrm{~km}$ & 0.1813 & 0.0013 & 0.1787 & 0.0007 \\
\hline MODprecip50km & 0.1378 & 0.0054 & 0.1397 & 0.0006 \\
\hline MODtemp $50 \mathrm{~km}$ & 0.1706 & 0.0004 & 0.1525 & 0.0004 \\
\hline Altitude $5 \mathrm{~km}$ & 0.2135 & 0.0008 & 0.0372 & 0.2228 \\
\hline Roughness $5 \mathrm{~km}$ & 0.0766 & 0.1200 & 0.1471 & 0.0048 \\
\hline LGMprecip $5 \mathrm{~km}$ & 0.1647 & 0.0080 & 0.0372 & 0.2315 \\
\hline LGMtemp $5 \mathrm{~km}$ & 0.2142 & 0.0007 & 0.1111 & 0.0176 \\
\hline LIGprecip $5 \mathrm{~km}$ & 0.1546 & 0.0065 & 0.1534 & 0.0021 \\
\hline LIGtemp $5 \mathrm{~km}$ & 0.2161 & 0.0010 & 0.0935 & 0.0440 \\
\hline MODprecip $5 \mathrm{~km}$ & 0.1665 & 0.0049 & 0.1060 & 0.0168 \\
\hline MODtemp $5 \mathrm{~km}$ & 0.2196 & 0.0003 & 0.0702 & 0.0832 \\
\hline
\end{tabular}

in distance between raw material use and other variables are considered. RawMat is most strongly correlated to Behaviour, followed by Timespace, with both Costpath and Age showing significant correlation to RawMat. Amongst environmental variables examined, only MODTemp $5 \mathrm{~km}$, LIGTemp $5 \mathrm{~km}$ and LGMPrecip $5 \mathrm{~km}$ distances do not show a significant correlation to differences in raw material use after $p$ value adjustment. Amongst environmental variables, temperature variables tend to show stronger correlation to raw material use, as do environmental variables at the $50-\mathrm{km}$ rather than $5-\mathrm{km}$ scale, with LGMTemp50km showing the strongest relationship, closely followed by LIGTemp $50 \mathrm{~km}$ and LIGPrecip50km. In contrast to Behaviour, terrain roughness is significantly correlated to RawMat at the $5-\mathrm{km}$ scale, but not the $50-\mathrm{km}$ scale, whereas altitude only shows a significant relationship to RawMat at the $50-\mathrm{km}$ scale. Differences in Site show a weaker but significant correlation to raw material distance in contrast to Method, which is not significant at an alpha $=0.05$ level.

\section{Partial Mantel tests}

The strongest correlation observed with Behaviour with simple Mantel tests was RawMat. When RawMat is controlled for, fourteen of twenty-two variables examined show substantive changes in the strength of correlations with Behaviour (> $10 \%$ change in test statistic) (Table 3). Variables with more limited change include Site, Roughness $50 \mathrm{~km}$, Altitude $5 \mathrm{~km}$, LGMPrecip $5 \mathrm{~km}, L$ GMTemp $5 \mathrm{~km}, L I G T e m p 5 \mathrm{~km}$ and $M O D P r e c i p 5 \mathrm{~km}$. The difference in Site, differentiating open-air sites from rock shelters and caves, exhibited a significant correlation with Behaviour, which may reflect choices made by archaeologists and past populations, as well as a factor of depositional contingency. When differences in Site are controlled for under a partial Mantel test, some modulations to correlation strength are observed, though only seven variables show a change $>10 \%$, with no change noted in significant correlations to Behaviour. The largest changes in strength of correlation occur for Roughness $5 \mathrm{~km}$ and Age, neither of which demonstrated a significant relationship to behavioural differences.

Notable correlation was identified between Behaviour and difference in both Altitude (both at $50-\mathrm{km}$ and $5-\mathrm{km}$ scales) and Roughness $50 \mathrm{~km}$. A number of substantive changes in the strength of correlation with Behaviour and significance of relationships are observed for environmental variables when either Altitude50km or Roughness50km are controlled for. When Altitude $50 \mathrm{~km}$ is controlled for, significant relationships occur between Behaviour and Roughness $50 \mathrm{~km}$, RawMat, Site and Timespace, whereas only the latter three variables retain significant relationships to Behaviour when Roughness $50 \mathrm{~km}$ is controlled for. When the various precipitation and temperature datasets are controlled for, a common pattern of impact 
on other environmental variables is observed, which are disregarded due to the impact of potential autocorrelations. Although the strength of correlations are modulated for non-environmental variables, these typically do not result in changes to significant relationships with Behaviour except for altitude variables, which may represent further autocorrelation between geography and climate.

Age showed weak but insignificant correlation to Behaviour, with no difference in the significance of correlations from the result of simple Mantel tests observed when it is controlled for, and modulation of test statistics is $<10 \%$ in all instances. When Costpath is controlled for, most variables show little difference in the strength or significance of correlations with Behaviour, with the exception of LIGPrecip $50 \mathrm{~km}$, which no longer show significant correlations. In the majority of cases, only minor modulation to the strength of correlations are observed when the extra-correlated variable Timespace is controlled for, whilst the correlations between Behaviour with LIGPrecip $50 \mathrm{~km}$ are no longer significant.

The results of partial Mantel tests examining the relationship between RawMat and other variables are presented in Table 4. Relatively minor modulations in the strength of correlations are observed to a small number of variables when Site is controlled for, without impacting the significance of any relationships with RawMat. Controlling for the impact of Behaviour, correlations between RawMat and Altitude $50 \mathrm{~km}, L$ GMTemp $5 \mathrm{~km}$, MODPrecip $5 \mathrm{~km}$, LGMPrecip50km and Site show a substantial drop in strength and are no longer significant, with more minor modulation across other variables that retain significant relationship to RawMat. Limited changes in the strength of correlations between RawMat and other variables are observed when Roughness $50 \mathrm{~km}$ is controlled for, although the relationship between RawMat and LIGTemp5km becomes significant at an alpha $=0.05$ threshold after $p$-adjustment. In contrast, more extensive changes in the strength of correlation to RawMat is observed when Altitude $50 \mathrm{~km}$ is controlled for, resulting in insignificant relationships between Site, LGMtemp $5 \mathrm{~km}$, $L G M$ precip $50 \mathrm{~km}$ and $M O D P r e c i p 5 \mathrm{~km}$. When alternate environment variables are considered, limited changes occur to other, non-environmental variables, with the relationship between differences in both Site and Altitude50km to RawMat repeatedly changing so that it is no longer significant. A single change occurs in the correlations between RawMat and other distance variables when Age is controlled for, with Site no longer showing a significant relationship to RawMat. When Costpath is controlled for, notable modulation of the strength of correlations to RawMat is observed across eleven variables, resulting in LGMprecip50km and Site no longer significantly correlated to RawMat. Controlling for Timespace, substantive changes in the strength of correlation between RawMat and sixteen other variables occur, resulting in insignificant relationships for Site, Altitude $50 \mathrm{~km}$, LGMPrecip $50 \mathrm{~km}$, LGMTemp $5 \mathrm{~km}$ and MODPrecip $5 \mathrm{~km}$.

\section{Multiple matrix regressions}

The alternate partial Mantel tests clearly show complex patterns of modulation of correlation between the variables under consideration and either Behaviour or RawMat, when the impact of individual variables is controlled for. Critically, it is difficult to constrain the impacts of spatial autocorrelations using Partial Mantel tests alone given the data sets employed, but multiple matrix regressions are able to limit their impact. Based on the results of simple testing above, we selected to use Age and Costpath, rather than Timespace, and to include MODprecip50 $\mathrm{km}$ and MODtemp $50 \mathrm{~km}$ datasets to characterise environment variables, alongside Rawmat, Roughness $50 \mathrm{~km}$, Site, Method and Altitude $50 \mathrm{~km}$. The results of multiple matrix regression for Behaviour are shown in Table 5.

These results show that when nine variables that may explain differences in artefact assemblage composition are examined, three exhibit independent effects on Behaviour. RawMat and Roughness50km have the most significant correlations to Behaviour. Site also shows significant correlation to artefact assemblage dissimilarity. The results of multiple matrix regression $\left(F\right.$-statistic: $59.829 ; r^{2}=0.13413 ; p=$ 0.0001 ) clearly indicate important correlations between Behaviour and the variables under examination here.

In the multiple matrix regression for RawMat, Behaviour shows the strongest, independent correlation to RawMat (Table 6) and Behaviour appears to play a stronger role in explaining RawMat than vice versa. Age and Costpath show significant, independent correlations to RawMat. Finally, Roughness $50 \mathrm{~km}$ shows a significant, independent correlation with RawMat. The results of multiple matrix regression ( $F$ statistic: $\left.55.992 ; r^{2}=0.1266 ; p=0.0001\right)$ show the variables examined here explain a comparable proportion of variability in RawMat to Behaviour, but differences exist as to which variables and the extent to which they explain this variability.

\section{Discussion}

These results show that distances in assemblage composition and raw material use significantly correlate with distances across a wide range of variables analysed. Multiple matrix regressions suggest that the variables examined here explain $\sim 13 \%$ of the variability for both stone tool assemblage composition and patterns of raw material use. In order to engage with the breadth of MSA assemblages across Eastern Africa, we have focused upon using the presence and absence of alternate artefact forms or raw material types. The suite of artefact forms employed combines types that represent 


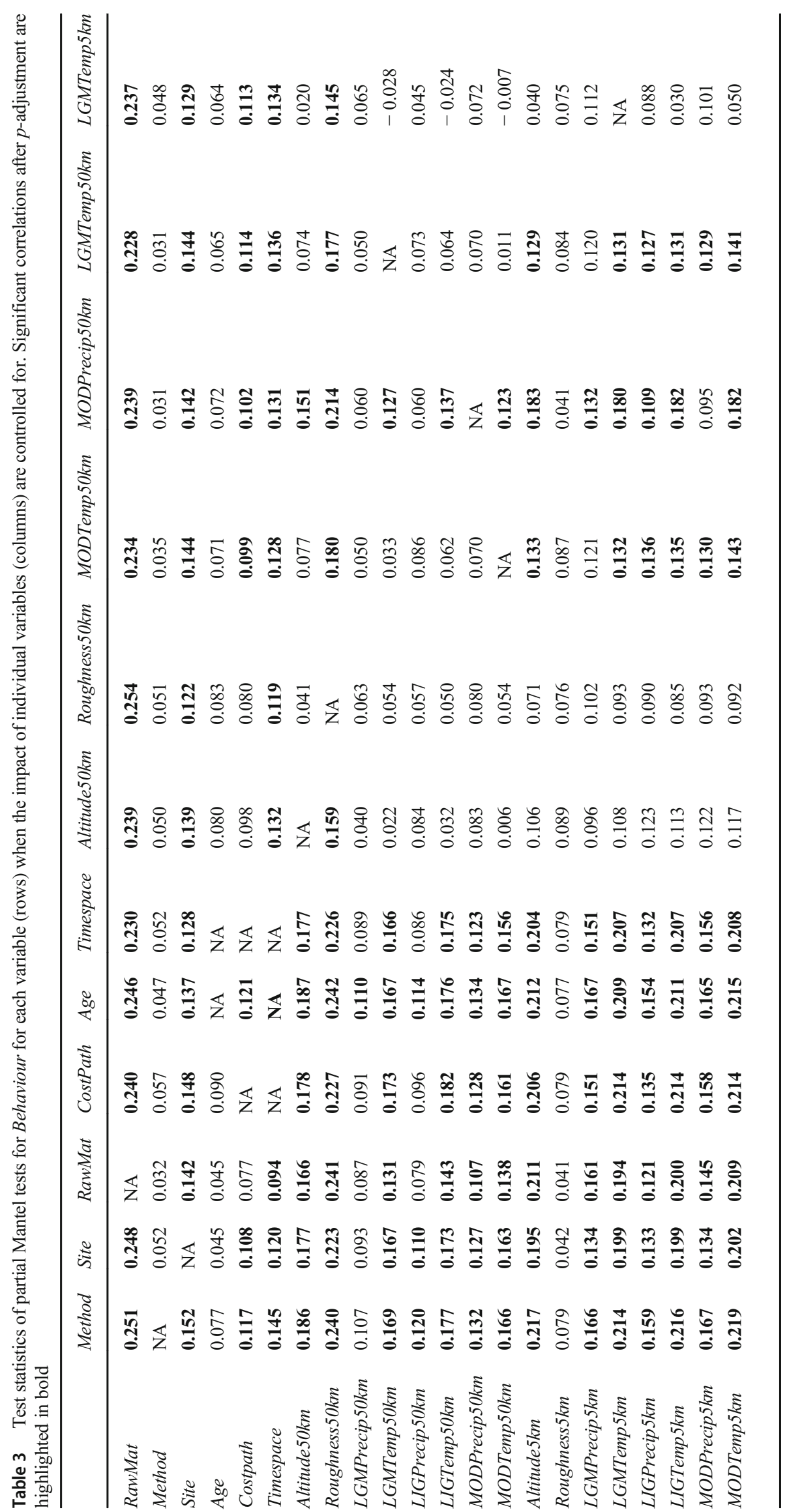




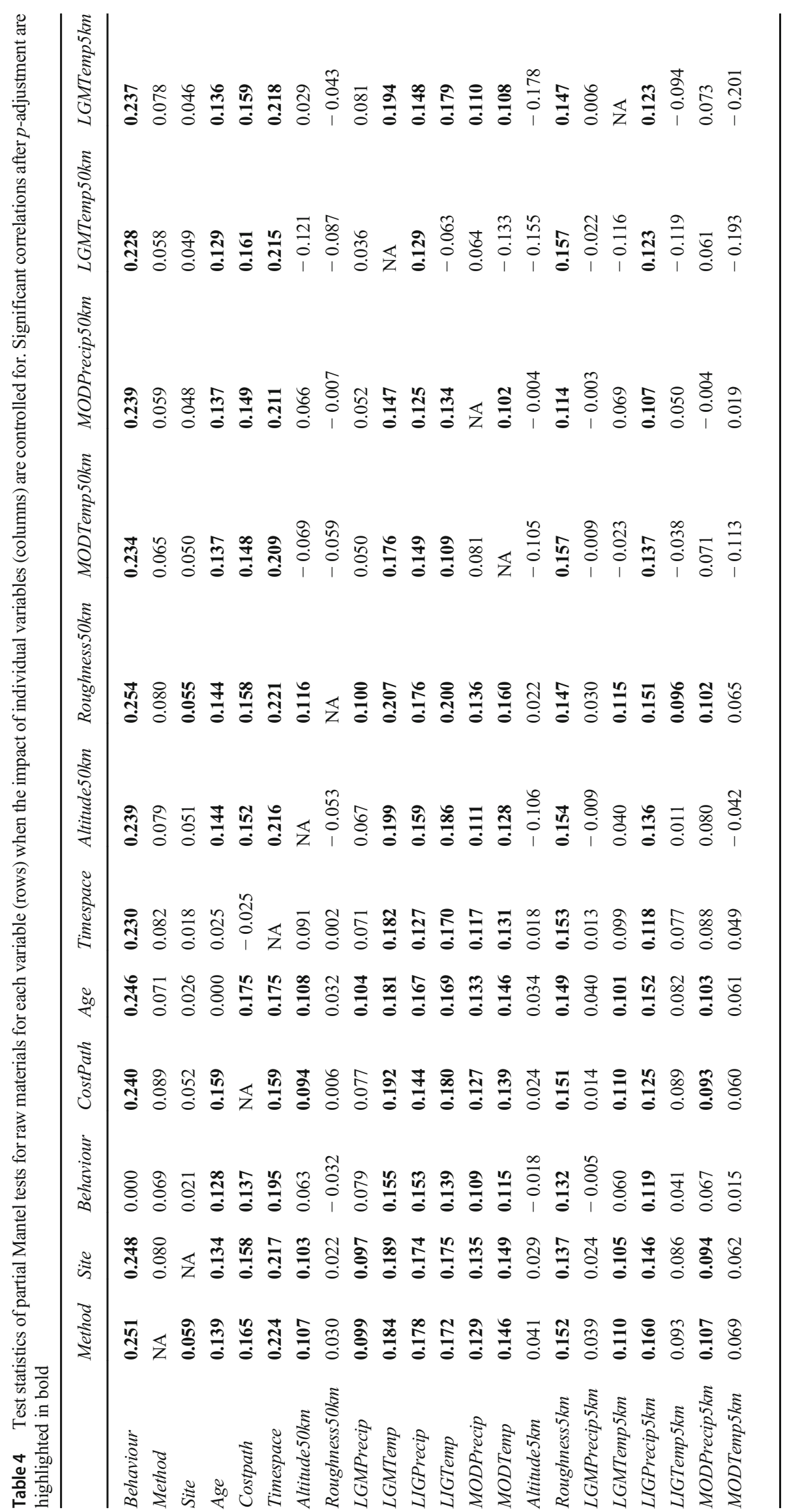


Table 5 Results of multiple matrix regression examining relationship between stone tool assemblage composition and other variables. Significant results are shown in bold

\begin{tabular}{llll}
\hline Variable & Estimate & $t$ value & $\operatorname{Pr}(>|t|)$ \\
\hline Roughness50km & $\mathbf{0 . 2 3 3 7 8 6}$ & $\mathbf{8 . 8 4 7 4 8 2}$ & $\mathbf{0 . 0 0 4}$ \\
RawMat & $\mathbf{0 . 1 5 7 2 5 4}$ & $\mathbf{1 3 . 6 5 8 7 5}$ & $\mathbf{0 . 0 0 0 1}$ \\
Site & $\mathbf{0 . 0 3 7 8 1 3}$ & $\mathbf{5 . 9 2 2 6 0 7}$ & $\mathbf{0 . 0 0 4 1}$ \\
Altitude50km & 0.0561 & 1.0742 & 0.764576 \\
MODTemp50km & -0.04076 & -0.95259 & 0.787879 \\
Costpath & 0.039207 & 2.60191 & 0.29603 \\
MODPrecip50km & 0.038595 & 2.136926 & 0.475248 \\
Age & 0.020509 & 1.587494 & 0.648565 \\
Method & 0.01232 & 1.812873 & 0.59886 \\
\hline
\end{tabular}

technological approaches (e.g. Levallois), key artefact forms (e.g. bifaces) and retouched tools that may exist on reduction continua (e.g. scrapers/denticulates). This complicates direct assessment of whether variability identified here relates to functional differences in tool use, but the possibility for redundancy in tool kits should be noted. For instance, both blade and Levallois blade strategies produce elongate blanks, with the choice of using either (or both) potentially relating to cultural choices or historical contingencies in patterns of cultural transmission that may help explain the large amount of unexplained variability.

Amongst the variables under consideration, distance in assemblage composition is most strongly correlated to differences in raw material use and vice versa, as identified by simple Mantel tests. The strength of correlations between raw material and behavioural distance is only marginally modified when other factors are controlled for in partial Mantel tests, preserving the strongest, significant relationship in all circumstances. This is further supported by the strong, significant relationships between behaviour and raw material distances identified under multiple matrix regressions. Critically, these results suggest that the relationships between raw

Table 6 Results of multiple matrix regression examining relationship between raw material use and other variables. Significant results are shown in bold

\begin{tabular}{llll}
\hline Variable & Estimate & $t$ value & $\operatorname{Pr}(>|t|)$ \\
\hline Behaviour & $\mathbf{0 . 3 2 3 9 1 8}$ & $\mathbf{1 3 . 6 5 8 7 5}$ & $\mathbf{0 . 0 0 0 1}$ \\
Costpath & $\mathbf{0 . 1 9 6 4 0 6}$ & $\mathbf{9 . 1 8 2 2 0 8}$ & $\mathbf{0 . 0 0 0 2}$ \\
Age & $\mathbf{0 . 1 3 8 5 3 3}$ & $\mathbf{7 . 5 2 9 2 7 9}$ & $\mathbf{0 . 0 0 8 6 0 1}$ \\
Energy50km & $\mathbf{- 0 . 2 1 9 2 6}$ & $\mathbf{- 5 . 7 4 4 6 7}$ & $\mathbf{0 . 0 1 4 5 0 1}$ \\
MODTemp50km & 0.212324 & 3.462657 & 0.235724 \\
MODPrecip50km & 0.076909 & 2.968773 & 0.225423 \\
Method & 0.026963 & 2.766217 & 0.305931 \\
Site & -0.00359 & -0.38968 & 0.812481 \\
Altitude50km & -0.02223 & -0.29656 & 0.919092 \\
\hline
\end{tabular}

material use and behavioural differences are largely independent from other factors that have been examined. Relatively few exclusive relationships can be identified when the presence/absence of raw material use and tool types are cross tabulated (Table 7). No RTBifacial tools are identified in assemblages that include the use of CCS, other igneous or other sedimentary raw materials. In addition, burins are absent from assemblages that use other sedimentary raw materials. The remaining fourteen artefact forms examined here are found to be included in lithic assemblages that overlap with the use of all raw material types, whereas all tool types are found to some extent in assemblages containing basalts, cherts, obsidian, metamorphics and quartzs. Eleven of the assemblages under consideration exhibit the use of a single raw material, with all others including a combination of multiple raw material types, including four assemblages that include six distinct raw material types. Finer resolution data is required to examine further the associations between particular tool types and raw materials, but from this dataset, it is apparent that the means to produce a diverse tool kit may have been managed through selection of diverse or complementary raw material resources.

Lithic raw material resources are not evenly spread across the landscape and their distribution may affect patterns of access and therefore use; this in turn may result in a degree of spatial autocorrelation in raw material use. Minimal impact on the strength of correlation between the difference in raw material use and behavioural distance is observed when cost path distance is controlled for in partial Mantel tests. However, in multiple matrix regressions, cost path distance shows independent correlation to raw material differences, supporting suggestions that a pattern of isolation by distance has some role in explaining diversity in the MSA records of Eastern Africa (Tryon and Faith 2013). When raw material use is controlled for in partial Mantel tests, the strength of correlations between behavioural distance and both geographic and environmental variables are notably reduced, with a comparable pattern observed when behavioural distance is controlled for and correlations to raw material distances analysed. This suggests that some modulation of assemblage composition and raw material use may reflect differences in physical landscapes and ecological contexts, but such modulation reflects a flexible means to engage with environmental diversity, rather than a rigid requirement for certain toolkits for occupation of certain habitats.

Differences in time appear to have a more substantive relationship to changing raw material use than varying assemblage compositions. Previous research has employed quantitative methods to successfully identify patterns of change through time in constellations of stone tool use (Blinkhorn and Grove 2018; Tryon and Faith 2013). The results of this study suggest that although constellations of stone tool types may change through time, isolation by time does not offer a 
Table 7 Proportions of assemblages that contain each combination of tool type and raw material type

\begin{tabular}{|c|c|c|c|c|c|c|c|c|}
\hline & Basalts (\%) & Cherts $(\%)$ & $\operatorname{CCS}(\%)$ & Obsidians (\%) & Metamorphics (\%) & $\begin{array}{l}\text { Quartzs } \\
(\%)\end{array}$ & $\begin{array}{l}\text { Other } \\
\text { igneous (\%) }\end{array}$ & $\begin{array}{l}\text { Other } \\
\text { sedimentary }(\%)\end{array}$ \\
\hline Backed_Microlith & 5 & 29 & 11 & 12 & 20 & 25 & 7 & 1 \\
\hline BipolarTech & 10 & 33 & 6 & 14 & 20 & 29 & 7 & 4 \\
\hline BladeTech & 30 & 52 & 11 & 38 & 27 & 43 & 17 & 6 \\
\hline Borer & 15 & 31 & 8 & 19 & 20 & 26 & 8 & 5 \\
\hline Burin & 1 & 7 & 5 & 12 & 8 & 7 & 5 & 0 \\
\hline CentripetalTech & 23 & 46 & 11 & 24 & 23 & 40 & 14 & 5 \\
\hline CoreTool & 20 & 31 & 10 & 17 & 15 & 26 & 13 & 2 \\
\hline Denticulate & 14 & 14 & 6 & 10 & 6 & 7 & 6 & 5 \\
\hline LevalloisBladeTech & 7 & 10 & 4 & 8 & 2 & 5 & 2 & 1 \\
\hline LevalloisFlakeTech & 31 & 56 & 14 & 30 & 32 & 49 & 21 & 6 \\
\hline LevalloisPointTech & 13 & 17 & 8 & 15 & 8 & 10 & 10 & 4 \\
\hline Notch & 14 & 30 & 6 & 19 & 18 & 29 & 5 & 4 \\
\hline PlatformCore & 18 & 37 & 4 & 23 & 14 & 37 & 7 & 2 \\
\hline PointTech & 32 & 54 & 12 & 36 & 26 & 43 & 13 & 7 \\
\hline RTBifacial & 2 & 14 & 0 & 1 & 17 & 17 & 0 & 0 \\
\hline Scraper & 30 & 54 & 14 & 38 & 25 & 45 & 14 & 6 \\
\hline
\end{tabular}

strong means to explain such patterns. However, the methods employed here may not fully account for pulsed changes in stone tool assemblage composition through time and particularly those that are identified at younger timeframes with shorter time differences between assemblages. Similarly, growing evidence suggests that substantial spatial structure exists within trajectories of change in the MSA during the Late Pleistocene, with the continuity of MSA technologies in regions such as highland Ethiopia whilst LSA technologies had become widely adopted in the Kenyan and Tanzanian Rift. The use of the extra-correlated Timespace variable presents one means to tackle this issue. Changing constellations of raw material use present a more discrete picture of change through time than modulations in assemblage composition in the MSA of Eastern Africa. Whilst no discrete patterns of exclusion occur, a notable shift in emphasis occurs from earlier assemblages which are more likely to include basalts to later assemblages that are more likely to contain quartz, with substantial overlap in preferences for both types occurring during MIS 5.

The different types of sites targeted correlate with patterns of behavioural distance. This appears to be independent of other factors that may have more directly affected past assemblage composition, as the strength and significance of relationships to behavioural distance remain largely unaffected when site type are controlled for, whilst the relationship between site type to behavioural distance remains comparable when other factors are controlled for in partial Mantel tests. Notably, site type shows significant independent correlations to behavioural distance in multiple matrix regressions. In contrast, differences between site types offer more limited means to explain differences in patterns of raw material use. This may partly reflect the alternate size of artefact and raw material inventories used, and the structure of past activities and tool use between open air compared to rock shelter or cave sites that may occur within landscapes with access to similar raw material resources.

Both assemblage composition and raw material use show significant relationships to differences in terrain roughness, but the nature of this relationship varies between these variables and between the analyses. Within simple Mantel tests, significant relationships were observed at different spatial scales, with distance in assemblage composition correlated to differences in roughness at the $50-\mathrm{km}$ scale whereas patterns of raw material use correlated to distance in roughness at a 5-km scale. Nevertheless, differences in terrain roughness at the $50-\mathrm{km}$ scale provide a substantial and independent means to explain variation in both assemblage composition and raw material use as identified in the multiple matrix regressions. Unlike either altitude or environmental variables, terrain roughness may not have direct relationships with patterns of ecology. However, roughness may substantively influence patterns of mobility and stone tool use across the landscape in which a site is situated. Differences in environmental conditions and altitude do show significant correlations to behavioural distance and raw material use, though a weaker relationship occurs between raw material use and altitude. It is notable that differences in temperature, rather than precipitation, typically exhibit the strongest correlations with patterns of assemblage composition and raw material use given the well-established relationship between temperature and biodiversity (Brown et al. 2004; Hamilton et al. 2016). However, 
neither modern temperature nor precipitation shows independent correlations in multiple matrix regressions, possibly indicating spatial autocorrelation with either terrain roughness or cost-path distances, though this would support the assertion that geographic rather than environmental factors play a more important role in explaining assemblage variability and patterns of raw material use. The LGM and LIG datasets, which offer a bracket for climatic extremities throughout a glacial cycle, do not show as close a relationship to behavioural distance as modern conditions. Some aspects of behavioural distance may be explained by different adaptations to different environmental (and ecological) conditions, although better terrestrial archives for environmental conditions may help constrain the use of modelled datasets.

The approach employed here deliberately targets the breadth of data available for the MSA of Eastern Africa, requiring a coarse resolution of analysis that is able to explain $12-13 \%$ of variability in patterns of stone tool assemblage composition and raw material use. Autocorrelation may explain why only one spatial variable is demonstrated to provide an independent correlation to patterns of assemblage composition and raw material use. The identification of terrain roughness as the spatial variable with the strongest relationship to both is notable given the heterogeneity of environmental conditions observed across Eastern African MSA sites, as well as occupations across a broad range of altitudes (Blinkhorn and Grove 2018). This is complemented by the significance of site type in explaining variability in stone tool assemblages. These results highlight the importance of the physical landscape in explaining artefact assemblage composition in the MSA of Eastern Africa over isolation by distance and time, though such factors could be mediated by the important impact they have on raw material use and its strong relationship with assemblage composition. Variability in stone toolkits appears significantly influenced by both the location of occupation and the cost of moving across a landscape. Stone Age hunter-gatherer mobility is often characterised as either comprising of logistical forays from a centre of occupation or as a number of seasonal moves of the residential base, though a spectrum of behaviour is likely obscured by such a dichotomy (Binford 1980, 2019). Reconciling our results with such models is not straightforward and is perhaps reliant upon the sparse, higher resolution sequences (e.g. Tryon et al. 2013), but we offer a complimentary approach that highlights the significance of examining mobility as a means to explain past behaviour and patterns of change. Patterns of raw material use also reflect how past mobile populations have engaged with their landscape. The spread of natural resources is uneven at both a local and regional scale whilstpatterns of raw material sourcing, lithic reduction and stone tool use may occur at discretelocations, both of which relate to patterns of isolation by distance in raw material use we identify. Similarly, patterns of isolation by time indicate changing preferences in raw material use through the MSA in Eastern Africa, which may reflect functional concerns regarding flaking properties of alternate materials, clast size availability and patterns of skill. Exotic raw material use, sourced from distances of ca. $300 \mathrm{~km}$, appears a persistent feature of the MSA of Eastern Africa (Brooks et al. 2018; van Baelen et al. 2019), and studies across the continent have illustrated that MSA populations have made costly choices to access raw materials that appear to exclude purely functional concerns (Nash et al. 2016). Examining how terrain roughness impacts the juxtaposition of locally sourced and exotic raw material use offers a profitable avenue for future inquiry, but one that is reliant upon detailed provenance analyses.

\section{Conclusions}

Earlier syntheses of the MSA of Eastern Africa struggled to clarify patterns of behavioural variability through space or time, emphasising the mosaic nature of the archaeological record (Clark 1988). The application of quantitative methods has begun to identify elements of structure within this mosaic record, illuminating changing patterns of behaviour (Tryon and Faith 2013; Blinkhorn and Grove 2018). Here, we have employed matrix correlations as a means to examine the extent to which variability between MSA stone tool assemblages and patterns of raw material use can be explained by a range of archaeological, behavioural and environmental factors, including the first application of multiple matrix regression to such datasets. The results of the study emphasise the significant relationship between alternate patterns of raw material use and different constellations of stone tools in an assemblage, with the former showing strong, independent correlations to differences in time and space. The combination of these two factors, as the single Timespace variable, exhibits stronger correlation to behavioural distances that are independent of other spatial variables under consideration, potentially indicative of the role cultural inheritance may play on processes of adaptation and innovation. Although isolation by distance appears to play some role in explaining differences in assemblage composition, a stronger relationship is identified with roughness, suggesting toolkit constellations may better reflect adaptation to mobility and use in landscapes with different topographies. This study also highlights the significant impact that choices made by archaeologists can have upon the archaeological record, especially with the prominence of archaeological method and focus on different site types in the results of multiple matrix regressions. Other geographic and environmental variables also illuminate significant relationships to behavioural variability, supporting the emphasis Basell (2008) placed on examining the ecological contexts of MSA sites in Eastern Africa. Identifying alternate means for examining the ecological contexts of 
archaeological sites, such as site-based palaeoenvironmental proxies or integration of faunal records, may help further resolve their impact on behavioural variability and disentangle impacts of spatial autocorrelations that result from using modelled climate data.

Supplementary Information The online version of this article (https://doi. org/10.1007/s12520-020-01250-8) contains supplementary material, which is available to authorized users.

Authors' contributions JB and MG both conceived the research, conducted the analyses and wrote the manuscript.

Funding Open Access funding enabled and organized by Projekt DEAL. This research has been supported by the Natural Environment Research Council as part of Grant: NE/K014560/1, “A 500,000-year environmental record from Chew Bahir, south Ethiopia: testing hypotheses of climate-driven human evolution, innovation, and dispersal", which forms part of the Hominin Sites and Paleolake Drilling Project. JB was supported by the Leverhulme Trust as part of the "Unravelling the pattern, impacts and drivers of early modern human dispersals from Africa" project (Grant Ref: RPG-2017-087).

Data availability All novel data sets are presented directly in the manuscript; other data used in the analyses are freely available and referenced with the text.

\section{Compliance with ethical standards}

Conflict of interest The authors declare that they have no conflict of interest.

Code availability No custom code was used in the analysis, and references to all software packages are presented in the text.Supplementary Information The online version of this article (https://doi.org/10.1007/ s12520-020-01250-8) contains supplementary material, which is available to authorized users.

Open Access This article is licensed under a Creative Commons Attribution 4.0 International License, which permits use, sharing, adaptation, distribution and reproduction in any medium or format, as long as you give appropriate credit to the original author(s) and the source, provide a link to the Creative Commons licence, and indicate if changes were made. The images or other third party material in this article are included in the article's Creative Commons licence, unless indicated otherwise in a credit line to the material. If material is not included in the article's Creative Commons licence and your intended use is not permitted by statutory regulation or exceeds the permitted use, you will need to obtain permission directly from the copyright holder. To view a copy of this licence, visit http://creativecommons.org/licenses/by/4.0/.

\section{References}

Ambrose SH, Deino Alan (2010) Technological diversity and geo- chronology ofMiddle Stone Age industries in the Central Rift Valley, Kenya: implications for the evolution of modern human behavior. Paleoanthropology 2010:A1
Andrefsky W (1994) Raw-material availability and the organization of technology. Am Antiq 59:21-34. https://doi.org/10.2307/3085499

Andrefsky W (2008) The analysis of stone tool procurement, production, and maintenance. J Archaeol Res 17:65-103. https://doi.org/10. 1007/s10814-008-9026-2

Bailey G (2007) Time perspectives, palimpsests and the archaeology of time. J Anthropol Archaeol 26:198-223. https://doi.org/10.1016/j. jaa.2006.08.002

Basell L (2008) Middle Stone Age (MSA) site distributions in eastern Africa and their relationship to Quaternary environmental change, refugia and the evolution of Homo sapiens. Quat Sci Rev 27:2484 2498. https://doi.org/10.1016/j.quascirev.2008.09.010

Binford LR (1980) Willow Smoke and dogs' tails: hunter-gatherer settlement systems and archaeological site formation. Am Antiq 45:4-20. https://doi.org/10.2307/279653

Binford LR (2019) Constructing frames of reference: an analytical method for archaeologyical theory building using ethnographic and environmental data sets. University of California Press, Berkeley

Blegen N (2017) The earliest long-distance obsidian transport: evidence from the $\sim 200 \mathrm{ka}$ Middle Stone age sibilo school road site, Baringo, Kenya. J Hum Evol 103:1-19. https://doi.org/10.1016/j.jhevol. 2016.11.002

Blinkhorn J, Grove M (2018) The structure of the Middle Stone Age of eastern Africa. Quat Sci Rev 195:1-20. https://doi.org/10.1016/j. quascirev.2018.07.011

Brandt S, Hildebrand E, Vogelsang R, Wolfhagen J, Wang H (2017) Journal of Archaeological Science : Reports A new MIS 3 radiocarbon chronology for Mochena Borago Rockshelter, SW Ethiopia : implications for the interpretation of Late Pleistocene chronostratigraphy and human behavior. J Archaeol Sci Rep 11: 352-369. https://doi.org/10.1016/j.jasrep.2016.09.013

Brooks AS, Yellen JE, Potts R, Behrensmeyer AK, Deino AL, Leslie DE, Ambrose SH, Ferguson JR, D'Errico F, Zipkin AM, Whittaker S, Post J, Veatch EG, Foecke K, Clark JB (2018) Long-distance stone transport and pigment use in the earliest Middle Stone Age. Science 360(80):90-94. https://doi.org/10.1126/science.aao2646

Brown JH, Gillooly JF, Allen AP, Savage VM, West GB (2004) Toward a metabolic theory of ecology. Ecology 85:1771-1789

Brown S, Savage PE, Ko AMS, Stoneking M, Ko YC, Loo JH, Trejaut JA (2013) Correlations in the population structure of music, genes and language. Proc R Soc B Biol Sci 281:20132072. https://doi.org/ $10.1098 / \mathrm{rspb} .2013 .2072$

Buchanan B, Hamilton MJ (2009) A formal test of the origin of variation in North American Early Paleoindian projectile points. Am Antiq 74:279-298

Bushozi P (2011) Lithic technology and hunting behaviour during the Middle Stone Age in Tanzania. University of Alberta, Edmonton

Clark JD (1988) The Middle Stone Age of East Africa and the beginnings of regional identity. J World Prehist 2:235-305. https://doi.org/10. 1007/BF00975618

Creanza N, Kolodny O, Feldman MW (2017) Cultural evolutionary theory: how culture evolves and why it matters. Proc Natl Acad Sci 114:7782-7789. https://doi.org/10.1073/pnas.1620732114

De la Torre I, Mora R, Arroyo A, Benito-calvo A (2014) Acheulean technological behaviour in the Middle Pleistocene landscape of Mieso ( East-Central Ethiopia ). J Hum Evol 76:1-25. https://doi. org/10.1016/j.jhevol.2014.06.008

Deino, A. L., Behrensmeyer, A.K., Brooks, A.S., Yellen, J.E., Sharp, W.D., 2018. Chronology of the Acheulean to Middle Stone Age transition in eastern Africa 2216, 1-8.

Dickson, D.B., Gang, G., 2002. Evidence of the emergence of "modern" behavior in the Middle and Later Stone Age lithic assemblages at Shurmai Rockshelter ( GnJm1) and Kakwa Lelash Rockshelter ( GnJm2 ) in the Mukogodo Hills of North-Central Kenya 19. 
Douze, K., 2012. Le Early Middle Stone Age d' Éthiopie et les changements techno-économiques à la période de 1 ' émergence des premiers Homo sapiens. L'Université Boredaux 1.

Eren MI, Durant AJ, Prendergast M, Mabulla AZP (2014a) Middle Stone Age archaeology at Olduvai Gorge. Tanzania Quat Int 323:292313. https://doi.org/10.1016/j.quaint.2013.12.042

Eren MI, Roos CI, Story BA, von Cramon-Taubadel N, Lycett SJ (2014b) The role of raw material differences in stone tool shape variation: an experimental assessment. J Archaeol Sci 49:472-487. https://doi. org/10.1016/j.jas.2014.05.034

Faith JT, Tryon CA, Peppe DJ, Beverly EJ, Blegen N, Blumenthal S, Chritz KL, Driese SG, Patterson D (2015) Paleoenvironmental context of the Middle Stone Age record from Karungu , Lake Victoria Basin, Kenya , and its implications for human and faunal dispersals in East Africa. J Hum Evol 83:28-45. https://doi.org/10.1016/j. jhevol.2015.03.004

Grove M, Blinkhorn J (2020) Neural networks differentiate between Middle and Later Stone Age lithic assemblages in eastern Africa. PLoSONE 15(8):e0237528. https://doi.org/10.1371/journal.pone. 0237528

Gutherz X, Diaz A, Ménard C, Bon F, Douze K, Léa V, Lesur J, Sordoillet D (2014) The Hargeisan revisited: lithic industries from shelter 7 of Laas Geel, Somaliland and the transition between the Middle and Late Stone Age in the Horn of Africa. Quat Int 343:69 84. https://doi.org/10.1016/j.quaint.2014.04.038

Hamilton MJ, Lobo J, Rupley E, Youn H, West GB (2016) The ecological and evolutionary energetics of hunter-gatherer residential mobility. Evol Anthropol 25:124-132. https://doi.org/10.1002/evan. 21485

Hublin J, Benncer A, Bailey SE, Freidline SE, Neubauer S, Skinner MM, Bergmann I, Le Cabec A, Benazzi S, Harvati K, Gunz P (2017) New fossils from Jebel Irhoud, Morocco and the pan-African origin of Homo sapiens. Nat Publ Gr 546:289-292. https://doi.org/10.1038/ nature 22336

Irpino A (2017) HistDAWass: histogram-valued data analysis. https:// doi.org/10.1007/s11634-014-0176-4

Jarvis A, HI Reuter A, Nelson EG, (2008). Hole-filled SRTM for the globe Version 4. Available from CGIAR-CSI SRTM $90 \mathrm{~m}$ Database. https://srtm.csi.cgiar.org

Kelly AJ (1996) Intra-regional and inter-regional variability in the East Turkana (Kenya) and Kenyan Middle Stone Age. PhD Thesis, Rutgers, The State University of New Jersey

Leakey MD, Hay RL, Thurber DL, Protsch R, Berger R (1972) Stratigraphy, archaeology, and age of the Ndutu and Naisiusiu beds, Olduvai Gorge, Tanzania. World Archaeol 3:328-341

Legendre P (2000) Comparison of permutation methods for the partial correlation and partial Mantel tests. J Stat Comput Simul 67:37-73. https://doi.org/10.1080/00949650008812035

Legendre P, Fortin MJ, Borcard D (2015) Should the Mantel test be used in spatial analysis? Methods Ecol Evol 6:1239-1247. https://doi. org/10.1111/2041-210X.12425

Leplongeon A, Pleurdeau D, Hovers E (2017) Late Pleistocene and Holocene lithic variability at Goda Buticha (southeastern Ethiopia): Implications for the understanding of the Middle and Late stone age of the horn of Africa. J Afr Archaeol 15(2):202-233

Loog L, Mirazón Lahr M, Kovacevic M, Manica A, Eriksson A, Thomas MG (2017) Estimating mobility using sparse data: application to human genetic variation. Proc Natl Acad Sci 114:12213-12218. https://doi.org/10.1073/pnas.1703642114

Lycett SJ (2018) Confirmation of the role of geographic isolation by distance in among-tribe variations in beadwork designs and manufacture on the High Plains. Archaeol Anthropol Sci 11:2837-2847. https://doi.org/10.1007/s12520-018-0742-3

Maíllo-Fernández JM, Marín J, Solano-Megías I, Uribelarrea D, MartínPerea D, Aramendi J, Medialdea A, Arteaga C, Pernas-Hernández M, Gidna A, Neogi S, Baudot E, Narváez C, Mabulla A (2019)
Victoria Cabrera Site: A Middle Stone Age site at Olduvai Gorge, Tanzania. Quaternary International 526:129-154

Mantel N (1967) Cancer research. Cancer Res 27:209-220. https://doi. org/10.1038/070279a0

McDougall I, Brown FH, Fleagle JG (2005) Stratigraphic placement and age of modern humans from Kibish, Ethiopia. Nature 433:733-736. https://doi.org/10.1038/nature03258

Mehlman MJ (1989) Late Quaternary archaeological sequences in northern Tanzania. Univeristy of Illinois, Champaign

Minetti AE, Gaudino P, Seminati E, Cazzola D, Minetti AE, Moia C, Roi GS, Susta D, Ferretti G, Holt NC, Askew GN, Minetti AE, Moia C, Roi GS, Susta D, Ferretti G, Alberto E, Moia C, Roi GS, Susta D, Ferretti G (2015) Energy cost of walking and running at extreme uphill and downhill slopes. J Appl Physiol 93:1039-1046. https:// doi.org/10.1152/japplphysiol.01177.2001

Nash DJ, Coulson S, Staurset S, Ullyott JS, Babutsi M, Smith MP (2016) Going the distance: mapping mobility in the Kalahari Desert during the Middle Stone Age through multi-site geochemical provenancing of silcrete artefacts. J Hum Evol 96:113-133

Oksanen, J., Blanchet, F.G., Friendly, M., Kindt, R., Legendre, P., Mcglinn, D., Minchin, P.R., O'hara, R.B., Simpson, G.L., Solymos, P., Henry, M., Stevens, H., Szoecs, E., Maintainer, H.W., 2019. Package "vegan" Title Community Ecology Package. Community Ecol. Packag. 2.

Ossendorf G, Groos AR, Bromm T, Tekelemariam MG, Glaser B, Lesur J, Schmidt J, Akçar N, Bekele T, Beldados A, Demissew S (2019) Middle Stone Age foragers resided in high elevations of the glaciated Bale Mountains, Ethiopia. Science 365:583-587

Parnell, A.C., 2018. Radiocarbon dating, age-depth modelling, relative sea level rate estimation, and non-parametric phase modelling. https://github.com/andrewcparnell/Bchron. https://doi.org/10.1002/ 9781118452547.ch32

Potts R, Behrensmeyer AK, Tyler Faith J, Tryon CA, Brooks AS, Yellen JE, Deino AL, Kinyanjui R, Clark JB, Haradon CM, Levin NE, Meijer HJM, Veatch EG, Bernhart Owen R, Renaut RW (2018) Environmental dynamics during the onset of the Middle Stone Age in eastern Africa. Science 360:86-90. https://doi.org/10.1126/ science.aao 2200

Revell LJ (2012) phytools: An R package for phylogenetic comparative biology (and other things). Methods Ecol Evol 3:217-223. https:// doi.org/10.1111/j.2041-210X.2011.00169.x

Rolland N, Dibble H (1990) A new synthesis of Middle Paleolithic variability. Am Antiq 55:480-499

Ross RM, Greenhill SJ, Atkinson QD (2013) Population structure and cultural geography of a folktale in Europe. Proc R Soc B Biol Sci 280:20123065. https://doi.org/10.1098/rspb.2012.3065

Scerri EML, Thomas MG, Manica A, Gunz P, Stock JT, Stringer C, Grove M, Groucutt HS, Timmermann A, Rightmire GP, d'Errico F, Tryon CA, Drake NA, Brooks AS, Dennell RW, Durbin R, Henn BM, Lee-Thorp J, deMenocal P, Petraglia MD, Thompson JC, Scally A, Chikhi L (2018) Did our species evolve in subdivided populations across Africa, and why does it matter? Trends Ecol. Evol. 33:582-594. https://doi.org/10.1016/j.tree.2018.05.005

Shea JJ (2008) The Middle Stone Age archaeology of the Lower Omo Valley Kibish Formation: excavations, lithic assemblages, and inferred patterns of early Homo sapiens behavior. J Hum Evol 55: 448-485. https://doi.org/10.1016/j.jhevol.2008.05.014

Shennan SJ, Crema ER, Kerig T (2015) Isolation-by-distance, homophily, and "core" vs. "package" cultural evolution models in Neolithic Europe. Evol Hum Behav 36:103-109. https://doi.org/10. 1016/j.evolhumbehav.2014.09.006

Shipton C, Roberts P, Archer W, Armitage SJ, Bita C, Blinkhorn J, Courtney-Mustaphi C, Crowther A, Curtis R, Errico FD, Douka K, Faulkner P, Groucutt HS, Helm R, Herries AIR, Jembe S, Kourampas N, Lee-Thorp J, Marchant R, Mercader J, Marti AP, Prendergast ME, Rowson B, Tengeza A, Tibesasa R, White TS, 
Petraglia MD, Boivin N (2018) 78,000-year-old record of Middle and Later stone age innovation in an East African tropical forest. Nat Commun 9:1832. https://doi.org/10.1038/s41467-018-04057-3

Slater, P.A., 2016. Change in lithic technological organization strategies during the Middle and Later Stone Ages in East Africa 10301922, 522.

Smouse PE, Long JC, Sokal RR (1986) Multiple regression and correlation extensions of the mantel test of matrix correspondence. Syst Zool 35:627-632. https://doi.org/10.2307/2413122

Tostevin GB (2013) Seeing lithics: a middle-range theory for testing for cultural transmission in the Pleistocene. Oxbow Books, Oakville

Tryon CA (2003) "Early" Middle Stone Age lithic technology of the Kapthurin formation (Kenya). Curr Anthropol 47:367-375

Tryon CA, Faith JT (2013) Variability in the Middle Stone Age of Eastern Africa. Curr Anthropol 54(S8):S234-S254. https://doi.org/ $10.1086 / 673752$

Tryon CA, Roach NT, Logan MAV (2008) The Middle Stone Age of the northern Kenyan Rift : age and context of new archaeological sites from the Kapedo Tuffs. J Hum Evol 55:652-664. https://doi.org/10. 1016/j.jhevol.2008.03.008

Tryon CA, Peppe DJ, Faith JT, Van A, Nightingale S, Ogondo J, Fox DL (2012) Archaeological Research in Africa Late Pleistocene artefacts and fauna from Rusinga and Mfangano islands , Lake Victoria, Kenya. Azania 47:14-38. https://doi.org/10.1080/0067270X.2011. 647946

Tryon CA, Crevecoeur I, Faith JT, Ekshtain R, Nivens J, Patterson D, Mbua E, Spoor F (2015) Late Pleistocene age and archaeological context for the hominin calvaria from GvJm-22. Proc Natl Acad Sci 112:2682-2687. https://doi.org/10.1073/pnas.1417909112
Tryon CA, Lewis JE, Ranhorn KL, Kwekason A, Alex B, Laird MF, Marean CW, Niespolo E, Nivens J, Mabulla AZP (2018) Middle and later stone age chronology of kisese II rockshelter (UNESCO World Heritage Kondoa Rock-Art Sites), Tanzania. PLoS One 13: 1-24. https://doi.org/10.1371/journal.pone.0192029

Van Baelen A, Wilshaw A, Griffith P, Noens G, Maíllo-Fernández JM, Foley RA, Lahr MM (2019) Prospect farm and the Middle and Later Stone Age occupation of Mt. Eburru (Central Rift, Kenya) in an East African context. Afr Archaeol Rev 36:397-417

van Etten J (2017) $R$ Package gdistance: distances and routes on geographical grids. J Stat Softw 76. https://doi.org/10.18637/jss.v076. i13

Walter RC, Buf RT, Bruggemann JH (2000) Early human occupation of the Red Sea coast of Eritrea during the last interglacial. Nature 405: $1-5$

Whittaker, J.C., Caulkins, D., Kamp, K.A., 1998. Evaluating consistency in typology and classification 5 .

Wright S (1943) Isolation by distance. Genetics 28:114-138. https://doi. org/10.5194/isprs-Archives-XLII-5-W1-419-2017

Yellen J, Brooks A, Helgren D, Tappen M, Ambrose S, Bonnefille R, Feathers J, Goodfriend G, Ludwig K, Renne P, Stewart K (2005) The Archaeology of Aduma Middle Stone age sites in the Awash Valley, Ethiopia. PaleoAnthropology 10:25-100

Publisher's note Springer Nature remains neutral with regard to jurisdictional claims in published maps and institutional affiliations. 